\title{
APONTAMENTOS SOBRE A PRODUÇÃO DO CONHECIMENTO CIENTÍFICO E A CONSTRUÇÃO DO CONCEITO DE HISTORICIDADE
}

\section{NOTES ON THE PRODUCTION OF SCIENTIFIC KNOWLEDGE AND THE CONSTRUCTION OF THE CONCEPT OF HISTORICITY}

RESUMO: Nesse artigo temos por objetivo refletir sobre alguns aspectos teóricos da produção do conhecimento científico, seus desdobramentos na produção do conhecimento e do saber histórico e a indicação de algumas preposições pertinentes à construção do conceito de historicidade.

Palavras-chave: Conhecimento científico. Teoria da história. Historicidade.

ABSTRACT: In this article we aim to reflect on some theoretical aspects of scientific knowledge production, its developments in the production of knowledge and historical knowledge and an indication of some prepositions relevant to the construction of the concept of historicity.

Keywords: Scientific knowledge. Theory of history. Historicity.

1 Professor de Teoria da História e História da Educação Brasileira do Programa de PósGraduação em Educação, da Universidade Nove de Julho, PPGE/Uninove. Água Branca - SP. 


\section{Introdução}

Existem diferentes definições de ciência construídas historicamente no mundo ocidental, abarcando uma vasta gama de tendências teóricas que pautaram o tema entre as suas mais sinceras preocupações intelectuais. Entre tantas definições possíveis de serem lembradas, damos aqui destaque àquelas que mereceram um exame minucioso nos meios acadêmicos; quais são elas: $\boldsymbol{0}$

empirismo lógico (incorporando-se nesta o racionalismo crítico) e o materialismo dialético, comumente chamado por marxismo.

Uma formidável concepção "racionalista crítica" de ciência é aquela que nos oferece Mário Bunge (1970, p. 26) quando afirma que esta "pode caracterizar-se como conhecimento racional, sistemático, exato, verificáveis e, por conseguinte, falível".

Outra interessante concepção produzida, agora, no interior do materialismo dialético é aquela que nos é a apresentada por Kedrov e Spukin (1966), para quem a ciência é um sistema de conhecimento em desenvolvimento, os quais se obtêm mediante os correspondentes métodos cognoscitivos e se refletem em conceitos exatos, cuja veracidade se comprova e se demonstra através da prática social. A ciência é um sistema de conceitos acerca dos fenômenos e leis do mundo externo e da atividade espiritual dos indivíduos, que permite prever e transformar a realidade em beneficio da sociedade; uma forma de atividade humana historicamente estabelecida, uma 'produção espiritual', cujo conteúdo e resultado são a reunião de êxitos orientados em um determinado sentido, de hipóteses e teorias elaboradas e das leis que constituem seu fundamento, assim como de procedimentos e métodos de investigação.

Em diferentes trabalhos publicados abordando questões problematizadoras da filosofia da ciência, existe um justificável interesse pelo empirismo lógico como uma corrente que tem produzido excelentes contribuições quanto à metodologia, dadas sua preocupação pelo modo de se 
obter o conhecimento. Isto é notório na definição de Bunge, especialmente quando retomamos sua afirmação final, que se apresenta de forma quase irônica: "e, por conseguinte, falível". Essa falibilidade da ciência significa para Bunge um constante desafio a seguir buscando a verdade. Esta atitude é digna de ser compartilhada.

A tônica da definição marxista é outra. A ênfase é dada pela intencionalidade do conhecimento, e a ideia de que o conhecimento serve para que o homem possa dominar a natureza e, ademais, o teste sobre a verdade do conhecimento científico é a prática social. É importante ressaltar que ambas as definições insistem que a ciência é um campo de conhecimento que cresce, cumulativamente, que esta em contínuo e permanente aumento, a diferença entre elas se dá na ênfase que uma da a como se obtêm o conhecimento, enquanto a ênfase da outra está em determinar para que sirvam estes conhecimentos.

Desta sorte, nesse artigo temos por objetivo refletir sobre alguns aspectos teóricos da produção do conhecimento científico, seus desdobramentos na produção do conhecimento e do saber histórico e a indicação de algumas preposições pertinentes à construção do conceito de historicidade.

\section{Características do conhecimento científico}

A matéria prima com que se tece a ciência são os conhecimentos. Segundo os marxistas Kedrov e Spirkin (1966, p. 37), "os conhecimentos significam o domínio de dados confirmados acerca dos fenômenos materiais e espirituais e sua acertada reflexão na consciência humana.".

Existem distintos tipos de conhecimento. De um lado, podemos dividir os conhecimentos em: cotidianos (ou vulgares), pré-científicos e científicos. De outro lado, em empíricos e teóricos. 
O conhecimento cotidiano deriva principalmente da informação sensorial sobre o mundo que nos cerca e da experiência acumulada cotidianamente em nossa interatividade constituinte da vida social. Trata-se de um conhecimento útil, muitas vezes verdadeiro, porém não tem como ser suficientemente verificado, nem é possível sistematiza-lo.

O conhecimento pré-científico é aquele que resulta da observação realizada pelo homem que Ihe permitem constatar e descrever fenômenos, todavia, por falta de sistematização, não é possível serem explicados plenamente.

O conhecimento empírico é aquele que se fundam, diretamente, nos dados disponíveis, verificáveis e introdutórios da possibilidade de construção de hipóteses e axiomas.

O conhecimento teórico (ou formal) é o que se cria através da elaboração mental, partindo ou não dos êxitos e/ou objetos concretos que thes possam interessar.

O conhecimento científico parte dos tipos de conhecimentos acima mencionados, porém os supera. Inclui a informação sensorial, a observação, a verificação e a elaboração teórica abstrata sistemática, de modo que não somente constata, descreve, classifica e explica os fenômenos, senão também os generaliza e desta forma obtêm leis e é capaz de fazer previsões. Os conhecimentos se transformam em científicos quando a acumulação de êxitos, realizada de acordo com uma orientação determinada e sua descrição alcançam tal nível de excelência, que podem ser incluídos num sistema de conceitos e formar parte de uma determinada teoria.

Defendemos a unidade da ciência. A divisão da ciência em diferentes disciplinas é um artifício arbitrário criado pelo homem diante da sua incapacidade de dominar todas as esferas do conhecimento. A ciência é uma só, mas estabeleceu-se uma divisão pragmática em seu interior, está é a realidade. Assim, nos encontramos num meio em que muitas disciplinas do conhecimento e do saber humano dispõe de um objeto concreto de estudos, 
outras - como é o caso da lógica e das matemáticas - não o tem. Bunge (1970, p. 26) sustenta que "eles (os lógicos e matemáticos) constroem seus próprios objetos [...] A matéria prima que usam os lógicos e matemáticos não é factual, senão ideal".

\section{Alguns aspectos sobre a produção do conhecimento e do saber histórico}

Evidentemente o presente texto não tem a mínima pretensão de sistematizar um conjunto de informações sobre a natureza do conhecimento histórico como uma das disciplinas constituintes do saber científico produzido no mundo ocidental. Um compromisso com uma análise deste porte nos exigiria um aprofundamento de questões como conceito de história e forma de história, por que estudamos história, o papel de correntes importantes como é o caso do positivismo, o relativismo e a fecundidade inquietante do marxismo, o problema da natureza dos fatos históricos, a explicação na perspectiva da história, a objetividade em história; além de estabelecer a necessária relação entre ideologia e história, estrutura e história e o aprofundamento da própria ideia de periodização, caso sejamos capazes de pensar o tempo como uma dimensão da crítica possível numa determinada época vivenciada pela humanidade.

As próprias transformações (e não evoluções) do pensamento ocidental inseridas no domínio da história teriam que ser necessariamente apreciadas, o que nos remeteria diretamente para questões pertinentes a uma Teoria da História e, portanto, uma inquebrantável disposição de estabelecer um plano de análise das obras de autores como Lucien Febvre, Marc Bloch, Fernand Braudel, P. Anderson, Pierre Vilar, Agnes Heller, A. Shaff e tantos outros quanto possam ser lembrados. O que aqui não temos condições de fazer. Podemos, contudo, apresentar, como estamos fazendo, alguns tópicos de 
Metodologia da História, porém, "em boa medida, a lógica, a técnica e a estratégia de uma pesquisa de campo dependem tanto de pressupostos teóricos quanto da maneira como o pesquisador se coloca na pesquisa e através dela e, a partir daí, constitui simbolicamente o outro que investiga." (BRANDÃO, 1999, p. 8).

A produção do conhecimento histórico pressupõe uma Metodologia da História, como uma disciplina especializada e articulada com a própria Metodologia Científica. Esta se deriva diretamente da Filosofia da Ciência, situando-se ao lado da Epistemologia e da Teoria. Diante disto, sumariamente, podemos dizer que a produção do conhecimento histórico obedece ao seguinte roteiro de problemas a serem resolvidos pelos seus artífices:

\section{A questão das fontes históricas.}

Chamamos de fonte histórica tudo quanto proporciona material para a reconstrução da vida do homem ao longo do tempo. O material mais usual e que constitui os alicerces do trabalho do historiador é normalmente chamado de documento. Este é pensado como um instrumento ou ato autêntico pelo qual se prova um direito. $\mathrm{O}$ documento valerá na medida de sua autenticidade: ele é conceituado, na pena de Robert Marichal (1961), como o conjunto de traços deixados pelo pensamento e pelos atos dos homens de outras épocas, esta definição aponta para os vestígios ou materiais preservados pelo tempo: utensílios, roupas, armas, monumentos, livros etc. Todos compõem o se convencionou chamar de fontes primárias.

\section{As fontes primárias.}

As fontes primárias são os registros dos atos e pensamentos dos homens de todas as épocas. As fontes primárias são necessariamente contemporâneas dos fatos que testemunham e se originam quer dos centros de decisão (poder público, instituições, etc.), quer de setores sociais significativos nas épocas a que se referem aos fatos estudados. É importante 
dizer que o estudo desses documentos exige certo preparo em técnica de pesquisa, dado que não basta uma "leitura" organizada, impondo-se certo interrogatório que obrigue o documento a "falar", captando-se muito mais o não dito do que o explicitado.

\section{As fontes secundárias.}

Aos trabalhos de interpretação histórica ou de reinterpretação da história chamamos de fontes secundárias. Em nosso universo social, normalmente, elas se constituem de livros, manuais, dicionários especializados e buscam fundamentar-se nas fontes primárias e, o que mais a caracteriza, é o fato dos acontecimentos históricos já aparecerem interpretados pelos analistas.

\section{A análise histórica.}

A análise é o desmembramento de um todo em seus elementos constitutivos. A esse desmembramento dá-se o nome de decomposição do objeto, pressupõe o prévio e minucioso exame da estrutura global. $O$ trabalho a ser realizado supõe que o pesquisador que a ele se entrega esteja adequadamente instrumentalizado de uma teoria. Como diziam nossos professores e colegas da velha guarda, a teoria precede à história e sem teoria não há nem História nem historiador.

No processo da análise podemos distinguir várias operações. Em primeiro lugar, temos a análise que identifica os componentes da totalidade a ser pesquisada e suas propriedades. Depois os procedimentos que se orientam no sentido da detecção das causas que respondem pela totalidade. Finalmente, a análise do todo enquanto totalidade visando a verificar os processos de interação com o exterior, ou seja, com outro todo já conhecido. Alguns teóricos preocupados com problemas metodológicos designam essas três operações pelos nomes de: análise molecular, análise funcional e análise global. Após essas operações atingimos a fase conclusiva, ou seja, a fase da síntese histórica. 


\section{A síntese histórica.}

A síntese histórica representa o procedimento de recomposição ou restauração da totalidade. Visa a estabelecer as relações de causalidade que envolve os fatos históricos em estudo. Como assinalam muitos críticos, é nesta fase que mais se constesta o sentido científico do saber histórico. Distinguemse dois tipos de procedimentos de síntese: (1) a síntese de reconstituição e (2) a síntese de explicação. Na síntese de reconstituição a preocupação do pesquisador se expressa pela organização dos fatos históricos em grupos homogêneos (políticos, religiosos, econômicos, culturais, etc.). Ocorre, ainda, a preocupação de se ordená-los em sequencias cronológicas e do estabelecimento de uma periodização.

No que se refere à síntese explicativa sua meta consiste na explicação dos eventos históricos. Precisamente neste ponto é que a possibilidade da história como ciência sofre contestação. O questionamento centraliza-se na adequação na adequação de procedimentos explicativos num espaço de saber caracterizado pela preocupação com o individual. Definida a explicação como subordinação de um fato a uma lei ela, na realidade, não parece pertinente em história e sobre este problema instala-se a polêmica.

\section{A crítica histórica.}

Sobre a crítica histórica precede, na verdade, a análise. Ela consiste no exame das informações. É no exercício da crítica que o historiador se legitima enquanto tal. Podemos dividi-la em crítica externa e crítica interna. $\mathrm{Na}$ primeira, também denominada de crítica de procedência, verifica-se a autenticidade do documento e o seu meio no sentido social do termo. Trata-se, neste último caso, de identificar a origem do documento e de que modo ele pode chegar até nossos dias. A importância atribuída às circunstâncias em que o documento foi elaborado faz com que alguns metodologistas da história prefiram denominar a crítica externa de crítica da autenticidade. Assim o fazem 
por considerarem as possíveis falsificações de textos históricos, o que comprometeria o trabalho de pesquisa.

A crítica externa ou de autenticidade divide-se em: crítica de procedência e crítica de restituição. Na primeira procura-se responder às seguintes perguntas: quem redigiu o documento? quando? onde? como? por que meios chegou até nós? A crítica da restituição permite obter pela via da comparação o melhor texto possível de um documento, cujo original não se encontra ou não mais existe.

A crítica interna é a própria interpretação do texto. Ela só se realiza após a crítica externa. Procura-se através dela, certificar-se do valor do documento. A crítica interna ou crítica de credibilidade se decompõe em cinco operações: a crítica de interpretação que analisa o conteúdo do documento para estabelecer o que o autor diz, como ele diz e o que queria dizer. A crítica da competência que procura saber como o autor chegou a conhecer o fato por ele narrado. A crítica da sinceridade verifica até que ponto houve fidelidade ou distorção dos fatos. A crítica da exatidão tem como objetivo verificar os erros involuntários cometidos pelo autor. Finalmente, a crítica dos testemunhos que compara o conteúdo do documento com o de outros testemunhos.

Convém acrescentar ainda uma observação importante neste contexto da crítica interna. Refere-se ao cuidado que se deve ter ao analisar criticamente um texto. Este cuidado repousa basicamente na linguagem própria do texto. A língua se modifica incessantemente e se ela é falada num espaço relativamente grande, varia segundo as regiões. Logo, o estudo da linguagem de um documento histórico nos conduz a descoberta dos hábitos de pensamento da época, das atitudes intelectuais, das mais variadas maneiras de sentir do meio produtor do texto.

De posse dessa atmosfera condicionada do documento ou texto, pode-se traçar um quadro geral das convenções sociais. Entre elas as relações sociais, expressa nas relações de produção material, e o sentimento de justiça que corporifica o conjunto dos valores expressos, por sua vez, no direito dessa 
sociedade, constituem os dados mais preciosos para a aquisição da imagem dessa época, contida literalmente ou não no documento.

Na pesquisa histórica contamos também com diversos instrumentos que nos ajudam no trabalho de análise. Nesse aspecto o trabalho dos que se dedicam ao exame historiográfico se constitui em ferramenta das mais valiosas e merece uma discussão toda especial.

\section{Construindo o conceito de historicidade}

O conceito de historicidade é um produto abstrato e teórico do que convencionamos chamar de História a qual tem, entre outros, os seguintes sentidos no mundo ocidental do qual fazemos parte:

a) Sentido etimológico - Trata-se de uma ciência, e caracteriza o estudo dos seres da natureza, com ou sem qualquer tipo de caracterização ou adjetivação do seu passado. Invariavelmente, este tipo de concepção é utilizado através da expressão "história natural" ou mesmo por uma crescente utilização da expressão "ciências naturais".

b) Sentido amplo, largo e imensurável - Convencionamos chamar de História o estudo de um passado qualquer.

c) Sentido estrito e mensurável - Chamamos de História o estudo do passado das experiências sociais que a humanidade foi capaz de desenvolver, ou este mesmo passado, tanto no sentido próprio (conhecimento ou narrativa do passado das sociedades humanas), como no sentido analógico (o passado e o devir das sociedades humanas), o que nos remete a uma concepção de História que não se já outra coisa do que uma concepção de História como filosofia ou uma Filosofia da História. 
Escrevendo sobre a História Jacques Le Goff nos informa que, "a palavra 'história' (em todas as línguas românicas e em inglês) vem do grego historie, em dialeto jônico. Esta forma deriva da raiz indo-europeia wid, weid, 'ver'. Daí o sânscrito vettas 'testemunha' e o grego histor 'testemunha' no sentido de 'aquele que vê'. Esta concepção da visão como fonte essencial de conhecimento leva-nos à ideia que histor 'aquele que vê' é também aquele que sabe; historein em grego antigo é 'procurar saber', 'informar-se'. Historie significa, pois 'procurar'. É este o sentido da palavra em Heródoto, no início das suas Histórias, que são 'investigações', 'procuras'. Ver, logo saber, é um primeiro problema".

Mas nas línguas românicas (e noutras), conforme nos ensina Le Goff (1997), "história" exprime dois, senão três, conceitos diferentes. Significa: I) esta 'procura das acções realizadas pelos homens' (Heródoto) que esforça por se constituir em ciência, a ciência histórica; 2) o objeto é o que os homens realizaram.

Por sua vez, se inspirando em Paul Veyne (1971), podemos dizer que a história é, quer uma série de acontecimentos, quer a narração desta série de acontecimentos. Mas a história pode ter ainda um terceiro sentido, o de narração. Uma história é uma narração, verdadeira ou falsa, com base na realidade histórica ou puramente imaginária - pode ser uma narração histórica ou uma fábula.

Pensando desta forma a História e entendendo a historicidade como um conceito que deriva daquele, uma concepção primária de historicidade precisa reconhecer que historicidade é o caráter daquilo que é histórico, ou seja, que pertence à história. No sentido fundacional e que permite a existência do conceito, é o sentido do que pertence à história objetiva, isto é, daquilo que se reconhece como realmente tendo-se passado, no sentido analógico, é o caráter disto ou daquilo que está integrado no devir/vir-a-ser humano, seja enquanto caráter do que vive, não no instante ou na eternidade, mas no tempo histórico 
socialmente construído e reconhecido, seja enquanto caráter daquilo que é contingente e varia com o tempo.

Desta forma, podemos dizer que, elucidar a historicidade de uma teoria ou de um fato cultural é, pois desvelar a tradição histórica que eles implicitamente supõem. Esse desvelamento deve conduzir a reflexão, inclusive, à explicitação do à priori universal que funda a continuidade da tradição e a arraiga nas invariantes do mundo da vida cotidiana. Assim, o questionamento da historicidade das produções do espírito opõe-se à história que se limita a acorrentar os fatos segundo uma causalidade exterior que deles não recupera a inteligibilidade intrínseca.

Em torno destas ideias primordiais, ao raciocínio até aqui desenvolvidos podem-se aduzir as seguintes proposições conclusivas:

a) Os fatos culturais supõem um percurso histórico (que podemos chamar de processo histórico) dialético a ser desvelado;

b) Esse processo compreende um continuum contraditório baseado num a priori

c) Universal que reconduz o percurso a invariantes existenciais;

d) Enquanto históricos, os fatos culturais escapam a proposições explicativas que os pretendem limitados ou reduzidos a efeitos fatal e exogenamente produzidos;

e) Logo, os fatos culturais (a História inclusive) ocorrem ou se produzem sob influências extrínsecas (a priori colocadas) e intrínsecas, entre as quais a ação humana. Tais fatos apresentam, ainda, uma dinâmica própria e contraditória, não se limitando, assim, a serem meros reflexos daquelas influências.

Compreender o conceito de historicidade pressupõe reconhecer que o homem (no sentido de humanidade) não pode compreender-se a não ser simultaneamente compreendendo as possibilidades ou condições que as coisas 
materiais exteriores Ihe apresentam ou impõem, e cuja finalidade ou intenção é por ele apreendida. Na medida em que ditas condições e finalidades são elevadas, como quer Heidegger, ao plano de "determinação ontológica do ser", ou seja, de determinação constitutiva do sentido do ser, decorre que a compreensão que define a historicidade do homem implica um círculo: toda compreensão do mundo implica a compreensão da existência, e vice-versa.

Disso resulta que, no conhecimento histórico, o saber não pode ser separado do sujeito para atingir o estatuto de objetividade que caracteriza as ciências exatas. Desvelamento do sentido do ser e compreensão, por parte deste, do seu próprio ser são dois aspectos inseparáveis da historicidade. $\mathrm{Na}$ medida em que participa da História e é histórico no seu próprio ser, o sujeito pode compreendê-la; por outro lado, essa compreensão é completamente limitada pela situação histórica particular na qual se efetua.

Não obstante, se o homem é um ser ontologicamente determinado pelas condições ou possibilidades que lhe são dadas e pela consciência que dessa sua condição de ser-situado, segundo a mesma perspectiva existencialista ele é também projeto, futurição, pelo que não se encontra nem cabal, nem fatalmente condenado a determinismos absolutos e inarredáveis.

Esta visão do homem supõe-no agente ativo de sua própria humanização e da construção do seu mundo. O homem, sujeito da cultura (com outros homens) e, portanto, da própria História, enquanto projeto continuamente está sendo; é um ser inconcluso e por isso inconclusa a sua obra, o que significa que o sentido das construções culturais é dinâmico, evolutivo (não sentido de linear, mas dialético), porque a busca do sentido é sempre um processo de reconstrução significante. Daí a vitalidade da Teoria da História que nos permite compreender que a interpretação do mesmo objeto (político, cultural, econômico, social) assuma significados diferentes, assim como a observação da mesma situação social possa suscitar ou não o fortalecimento de uma determinada historiografia. Tudo depende, pois, do "clima", ou seja, das condições histórico-sociológicas - em determinado lugar e 
momento - serem ou não facilitadoras, impulsionadoras ou elucidadoras da intervenção do historiador e do domínio do cabedal teórico que este socialmente foi capaz de assimilar.

Para o homem agir no/sobre o mundo é necessário compreendê-lo, e isto pressupõe e implica consciência e compreensão da própria existência, portanto, das condições em que esta se dá, como já observamos anteriormente. E como a existência humana é coexistência ou convivência situada, (3) a conclusão necessária é que a História (assim como os fatos culturais) ocorre sob o influxo de fatores extrínsecos (a priori colocados) e intrínsecos (entre os quais a ação humana), donde se infere que a História pode ser feita, sim, todavia, sob condições determinadas e na dependência de vontades várias, individuais ou coletivas. Neste sentido, aliás, é de toda apropriada à afirmação de José Ferrater Mora de que "a historicidade não é para Heidegger a característica da história simplesmente enquanto passado, senão o traço fundamental daquilo que pode ser chamado 'a possibilidade de construir a história'. Se se prefere, não é a historicidade que resulta da história, mas, esta é que resulta daquela". (MORA, 1978, p. 857)

A sociologia do conhecimento, particularmente na ótica aguçada de um Karl Mannheim, procura demonstrar que todo conhecimento é socialmente condicionado. Interpretando a visão mannheimiana do processo do conhecimento, Adam Schaff (1982) sustenta que entre as opiniões dos homens sobre os problemas sociais e as condições sociais que thes são próprias uma relação nunca banal se estabelece. $O$ fato de os homens terem precisamente certas opiniões com exclusão de outras decorre, segundo ele, de estarem em determinada época e em determinadas condições.

Por outro lado, para atuar no/sobre o mundo o homem necessita saber, querer e poder. Dizendo-se de outra forma, o agir humano tem como pressupostos o conhecimento, a motivação e a possibilidade, inclusive disponibilidade de alternativas. A direção e intensidade da conduta humana variam, assim, na conformidade desses pressupostos, os quais, por sua vez, 
são condicionados pela personalidade (características pessoais adquiridas através da comunicação social) de cada indivíduo e pela compatibilidade com as invariantes estruturais e conjunturais do lugar e momento (pensado como época) em que estão situados o sujeito ativo e os demais protagonistas.

Feitas estas considerações, algumas precisões ainda podem ser feitas, em adição às proposições até agora observadas:

a) A historicidade é uma dimensão inerente à condição humana (portanto, do homem), e é por este ao mundo imprimido enquanto sujeito de relações inter-humanas;

b) Por conseguinte, esta historicidade é inseparável da história da civilização, porquanto o homem é um ser-no-mundo, e só por sua presença compartilhada esse mundo se faz espaço de civilização e cultura;

c) Essa historicidade constitui, no entanto, apenas mais uma dimensão do homem, aquela do "estar-sendo" e do "vir-a-ser": o ser humano é capaz de assimilar outras dimensões ao seu próprio existir, entre as quais a dimensão de transcendentalidade, pela qual e em função da quais valores morais e espirituais são individual e coletivamente cultivados;

d) Agindo no/sobre o mundo, o homem se constrói e, na medida em que se compreende enquanto ser histórico (mas condicionado) assume-se como sujeito da história, pressupondo-se-lhe presentes conhecimentos, motivações e possibilidades alternativas de ação, além de interferentes a consciência e a avaliação de sua transcendental idade.

\section{Considerações finais}

A dimensão humana da historicidade não deve ser confundida com a "consciência da instabilidade das coisas terrestres", nem nada tem a ver com a crença em um universo regido por uma lei inexorável pela qual o homem só 
teria que avançar ("evolução"): a primeira conduz ao ceticismo; e a segunda, ao fatalismo; ao passo que o sentido da dimensão histórica remete a pessoa a si mesma e a sua atividade. Portanto, para um humanismo animado pelo sentido da história: há um mundo melhor a construir, uma justiça mais ampla a realizar, um futuro a edificar que seja mais digno do homem e permita um mais efetivo reconhecimento do homem pelo homem, à superação da exploração do trabalho e a finalização da opressão que arruína irremediavelmente a condição humana.

Finalizando, podemos dizer que a historicidade dos fatos sociais compreende-se na ação humanos a partir dos planos individual e coletivo (da intersecção permanente entre eles), ambos temporal e espacialmente situados, o que subentende que os fatores ou características de índole individual e societária conjugam-se a especificidades ou propriedades da época e lugar em que a ação se desenvolve.

Em nível individual, a situação humana varia segundo as condições orgânicas (situação física, saúde, idade, sexo), psicológicas (temperamento, nível de satisfação e aspiração) psicossociais e culturais da pessoa (grau de escolaridade, participação social e política, nível de consciência: mágico, ingênuo ou crítico) etc. Todas estas variáveis podem contribuir para que o indivíduo atue mais ou menos intensamente no sentido de influir sobre a vida social, portanto, sobre a produção dos fatos culturais, sobretudo dos fatos históricos, que são produzidos mediante uma interpretação meticulosa e consciente daquele que se dispõe a realizar tal ofício, particularmente, na edificação do universo social da educação e sua história.

\section{Referências bibliográficas e obras de apoio.}

BRANDÃO, C. R. Repensando a pesquisa participante. São Paulo: Brasiliense, 1999. 
BUNGE, Mario. La ciencia, su método y su filosofia. Buenos Aires: Siglo Veinte, 1970.

CARR, E. D. Que é história? São Paulo: Paz e Terra, 1982.

COLLINGWOOD, R. G. A ideia de história. Lisboa: Presença, 1965.

KEDROV, M.B. \& SPIRKIN, A. La ciencia. México, México: Ed. Grijalbo, 1966.

MARICHAL, Robert. La critique des textes. In: VHistoire et vc.v méthodes.

Paris, Gallimard, 1961.

MORA. J. F. Dicionário de filosofia. Lisboa: Publicações Dom Quixote, 1978.

LE GOFF, J. Enciclopédia Einaudi. V. 1. Memória - História. Verbete História.

Porto: Imprensa Nacional \& Casa da Moeda, 1997.

SCHAFF, A. História e verdade. São Paulo: Martins Fontes, 1982.

VEYNE, P. Como se escreve a História. Lisboa: Edições 70, 1971.

Enviado em 24 de abril de 2012. Aprovado em 27 de agosto de 2012. 